\title{
Erratum: Low-threshold amplified spontaneous emission and lasing from colloidal nanocrystals of caesium lead halide perovskites
}

Sergii Yakunin, Loredana Protesescu, Franziska Krieg, Maryna I. Bodnarchuk, Georgian Nedelcu, Markus Humer, Gabriele De Luca, Manfred Fiebig, Wolfgang Heiss \& Maksym V. Kovalenko

Nature Communications 6:8056 doi: 10.1038/ncomms9056 (2015); Published 20 Aug 2015; Updated 23 Sep 2015

In Fig. $5 \mathrm{~d}$ of this Article, a shaded box was inadvertently placed over the lower part of the panel during the final stages of production. The correct version of the figure appears below.
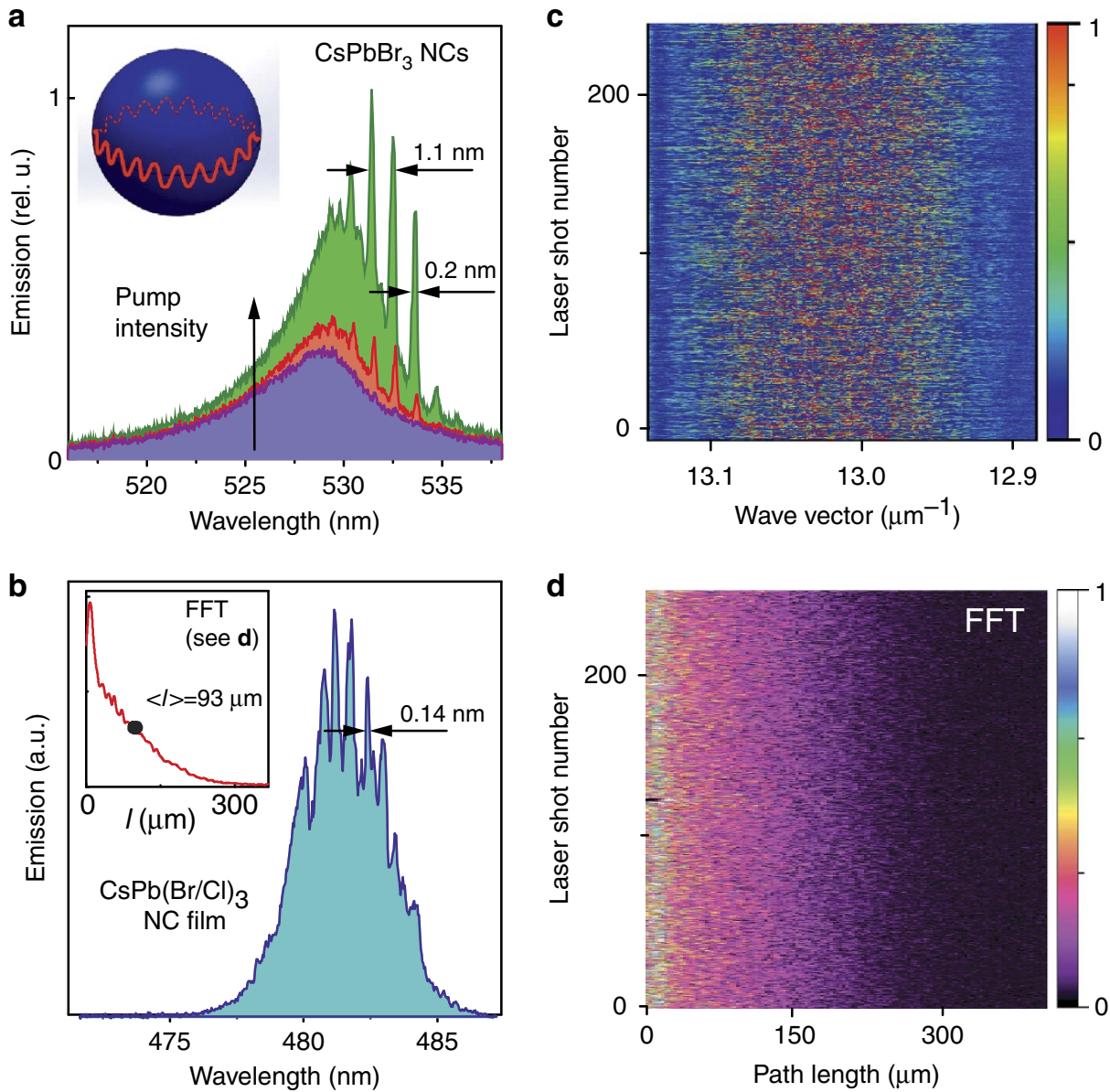

Figure 5

(c) This work is licensed under a Creative Commons Attribution 4.0 International License. The images or other third party material in this article are included in the article's Creative Commons license, unless indicated otherwise in the credit line; if the material is not included under the Creative Commons license, users will need to obtain permission from the license holder to reproduce the material. To view a copy of this license, visit http://creativecommons.org/licenses/by/4.0/ 